2012

\title{
The Role of Larval Dispersal in Metapopulation Gene Flow: Local Population Dynamics Matter
}

Daphne M. Munroe

John M. Klinck

Old Dominion University, jklinck@odu.edu

Eileen E. Hofmann

Old Dominion University, ehofmann@odu.edu

Eric N. Powell

Follow this and additional works at: https://digitalcommons.odu.edu/oeas_fac_pubs

Part of the Marine Biology Commons, and the Oceanography Commons

\section{Repository Citation}

Munroe, Daphne M.; Klinck, John M.; Hofmann, Eileen E.; and Powell, Eric N., "The Role of Larval Dispersal in Metapopulation Gene Flow: Local Population Dynamics Matter" (2012). OEAS Faculty Publications. 139.

https://digitalcommons.odu.edu/oeas_fac_pubs/139

\section{Original Publication Citation}

Munroe, D.M., Klinck, J.M., Hofmann, E.E., \& Powell, E.N. (2012). The role of larval dispersal in metapopulation gene flow: Local population dynamics matter. Journal of Marine Research, 70(2-3), 441-467. doi: 10.1357/002224012802851869 


\title{
The role of larval dispersal in metapopulation gene flow: Local population dynamics matter
}

\author{
by Daphne M. Munroe ${ }^{1,2}$, John M. Klinck ${ }^{3}$, Eileen E. Hofmann ${ }^{3}$ \\ and Eric N. Powell ${ }^{1}$
}

\begin{abstract}
The degree of genetic connectivity among populations in a metapopulation has direct consequences for species evolution, development of disease resistance, and capacity of a metapopulation to adapt to climate change. This study used a metapopulation model that integrates population dynamics, dispersal, and genetics within an individual-based model framework to examine the mechanisms and dynamics of genetic connectivity within a metapopulation. The model was parameterized to simulate four populations of oysters (Crassostrea virginica) from Delaware Bay on the mid-Atlantic coast of the United States. Differences among the four populations include a strong spatial gradient in mortality, a spatial gradient in growth rates, and uneven population abundances. Simulations demonstrated a large difference in the magnitude of neutral allele transfer with changes in population abundance and mortality (on average between 14 and $25 \%$ depending on source population), whereas changes in larval dispersal were not effective in altering genetic connectivity (on average between 1 and $8 \%$ ). Simulations also demonstrated large temporal changes in metapopulation genetic connectivity including shifts in genetic sources and sinks occurring between two regimes, the 1970s and 2000s. Although larval dispersal in a sessile marine population is the mechanism for gene transfer among populations, these simulations demonstrate the importance of local dynamics and characteristics of the adult component of the populations in the flow of neutral alleles within a metapopulation. In particular, differential adult mortality rates among populations exert a controlling influence on dispersal of alleles, an outcome of latent consequence for management of marine populations.
\end{abstract}

\section{Introduction}

Considerable attention has been focused on the mechanisms and dynamics of genetic connectivity among populations within a metapopulation (Pannell and Charlesworth, 2000; Hellberg, 2009). The degree of connectivity among populations has direct consequences for species evolution, development of disease resistance, and capacity of a metapopulation to adapt to climate change (Levin, 2006; Cowen and Sponaugle, 2009; Connolly and Baird, 2010). Field-based estimates of genetic connectivity have progressed enormously in recent

1. Rutgers University, Institute of Marine and Coastal Sciences and The New Jersey Agricultural Experiment Station, Haskin Shellfish Research Laboratory, Port Norris, New Jersey, 08349, U.S.A.

2. Corresponding author. email: dmunroe@hsrl.rutgers.edu

3. Center for Coastal Physical Oceanography, Department of Earth \& Atmospheric Sciences, Old Dominion University, Nofolk, Virginia, 23529, U.S.A. 
years, but nevertheless often provide ambiguous results (Piggott et al., 2008; White et al., 2010), and thus population genetics models increasingly have been implemented to study population genetic connectivity (Johnson and Gaines, 1990; Palumbi, 2003; Epperson et al., 2010; Galindo et al., 2010; Pujolar et al., 2011).

Integration of ecological and genetic metapopulation models provides an important tool for understanding the complexities of population connectivity (Hastings and Harrison, 1994; Levin, 2006; Epperson et al., 2010; Frank et al., 2011; Lamy et al., 2012). Consequently, much recent effort has been made to incorporate dispersal and population genetics in models of terrestrial (Landguth and Cushman, 2010) and marine (Pujolar et al., 2011; Rivera et al., 2011; White et al., 2011) systems. However, these simulation modeling efforts do not consider the interactions of larval connectivity with populations genetics. Clarification of the interactions of larval connectivity and population genetics is essential to fisheries management and the design of marine protected areas (Guichard et al., 2004; Frank et al., 2011). The metapopulation model used in this study expands an age-structured single-population genetics model (Powell et al., 2011c,d) into a spatially-explicit metapopulation model with population connectivity determined by larval transport. This approach presents a novel and powerful framework that melds population dynamics, dispersal, and genetics and allows examination of metapopulation processes within an individual-based model framework.

Modeling approaches are particularly useful for studying genetic connectivity in the marine environment that is normally characterized by greater larval dispersal distances (Scheltema, 1971; Botsford et al., 2003; Piggott et al., 2008) and by species with higher fecundity than is typical for the terrestrial realm (Strathmann, 1990; Hedgecock et al., 2007). In populations of sessile marine organisms where adults are immobile, this distinction becomes even more apparent because connectivity among populations occurs only by dispersal of larval stages; larvae are the only vector for gene transfer among sessile marine populations. Field studies of these larval stages and their movement are hampered by their small size and tracking difficulty (Underwood and Keough, 2001). As a consequence, models of larval dispersal in marine systems have been used to help quantify connectivity among populations (Levin, 2006; Piggot et al., 2008; Galindo et al., 2010; Rivera et al., 2011; White, 2011).

The traditional Levin's $(1969,1970)$ model of a metapopulation derives from extinction and recolonization dynamics of individual populations; however, this may not be the common model of marine metapopulations (Grimm et al., 2003; Kritzer and Sale, 2004). Here we employ a more general metapopulation concept. We define a metapopulation as a group of populations with two key characteristics; (i) each population has its own distinct dynamics and (ii) populations are connected by migration or dispersal. For sessile marine invertebrates such as oysters, dispersal is controlled by hydrodynamics (Bertness et al., 1996; Pineda, 1999; Gawarkiewicz, 2007), larval swimming behavior (DiBacco et al., 2001; Metaxas, 2001; Shanks and Brink, 2005), and larval life span (Grantham et al., 2003). Understanding and management of marine systems commonly employs a metapopulation approach and in doing so, must incorporate population dynamics and larval connectivity in 
management decisions and strategies. These two characteristics can influence the degree of genetic connectivity among populations, which has far reaching implications for metapopulation evolution, disease resistance, and adaptation to climate change (Levin, 2006; Cowen and Sponaugle, 2009; Connolly and Baird, 2010).

Eastern oysters (Crassostrea virginica) in Delaware Bay provide a useful example metapopulation for studying the processes governing genetic connectivity. This metapopulation underwent a rapid genetic response to MSX (Haplosporidium nelsoni) disease pressure over the period of only 2 years during the mid-1980's resulting in a nearly disease-resistant metapopulation being derived from one that previously was relatively highly infected (Ford et al., 1999; Hofmann et al., 2009). This rapid shift suggests that the metapopulation is well connected genetically (see also He et al., this issue). The estuary is characterized by a salinity gradient that establishes spatial variability in population parameters from the lower bay through the upper bay (Powell et al., 2008). In addition, extensive time series exist demonstrating temporal variability in population parameters. Oysters in Delaware Bay are an important fishery resource that has been surveyed as a metapopulation for management of the fishery since the 1950's. The comprehensive time series for this stock shows distinctive population dynamics in the 1970s versus the 2000s. During the 2000s, an upbay/downbay gradient in mortality and abundance of oysters existed such that abundance increased and mortality decreased upbay. In the 1970s, abundance was high and mortality low over the entire range of the stock (Powell et al., 2008).

The two potential influences on genetic connectivity, larval dispersal and post-settlement population dynamics, can be examined by comparing simulations of genetic connectivity between the two distinctive decades of the 1970s and 2000s. Here, we use simulations from a spatially-explicit individual-based metapopulation model of Delaware Bay oysters to make this comparison. We focus on the transmission of neutral alleles among populations to quantify the degree of genetic connectivity. Further, to examine how larval dispersal and post-settlement population dynamics influence genetic connectivity, we use sensitivity analysis examining how variations in larval dispersal and post-settlement population processes among the constituent populations influence genetic connectivity. We then contrast the roles that larval dispersal and within-population dynamics play in determining the degree of genetic connectivity between populations across the estuarine environmental gradient.

\section{Materials and methods}

\section{a. The model}

The Dynamic Population Genetics Engine (DyPoGEn) is a spatially-explicit numerical model that simulates genetic structure and population dynamics for a metapopulation. The metapopulation model builds on a previously developed single population model by simultaneously simulating multiple populations and linking these simulated populations with larval dispersal (Powell et al., 2011c,d). The model was parameterized to simulate a metapopulation containing four connected populations of eastern oysters (Crassostrea virginica) from 


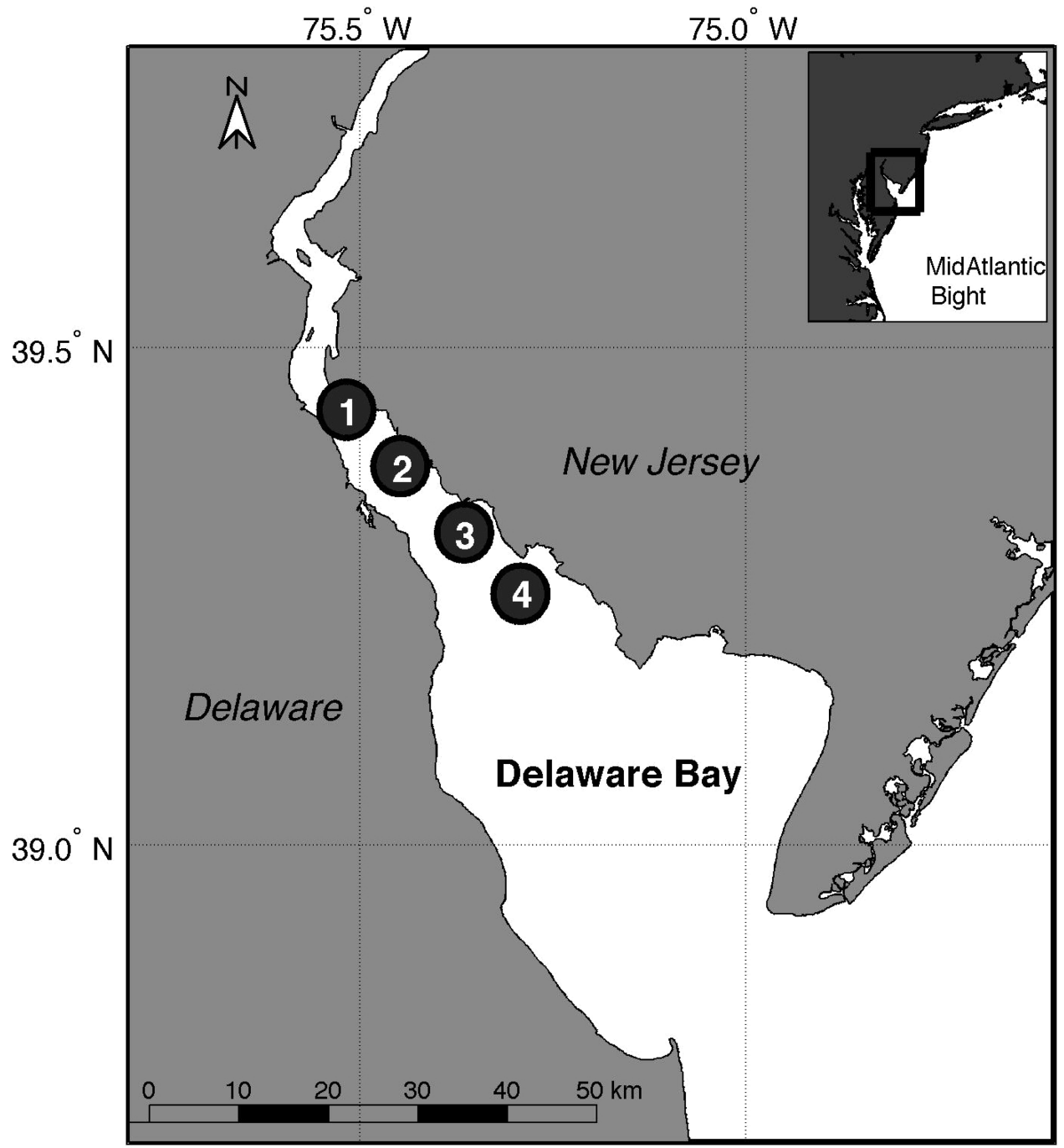

Figure 1. Map of locations of oyster populations in Delaware Bay used in simulations. Inset shows location of Delaware Bay on the Atlantic Coast of the U.S.

Delaware Bay on the Mid-Atlantic coast of the United States using comprehensive oyster population data from fishery stock assessments for the years 1970-1979 and 2000-2010 (Powell et al., 2009a,b; 2011a). Locations of the four populations within Delaware Bay are shown in Figure 1. The model allows independent control of populations within the metapopulation for parameters such as adult, juvenile and larval mortality, local carrying capacity, animal growth rate, fecundity, initial genotype frequency, and larval connectivity. Populations within the metapopulation interact via larval dispersal such that larvae 


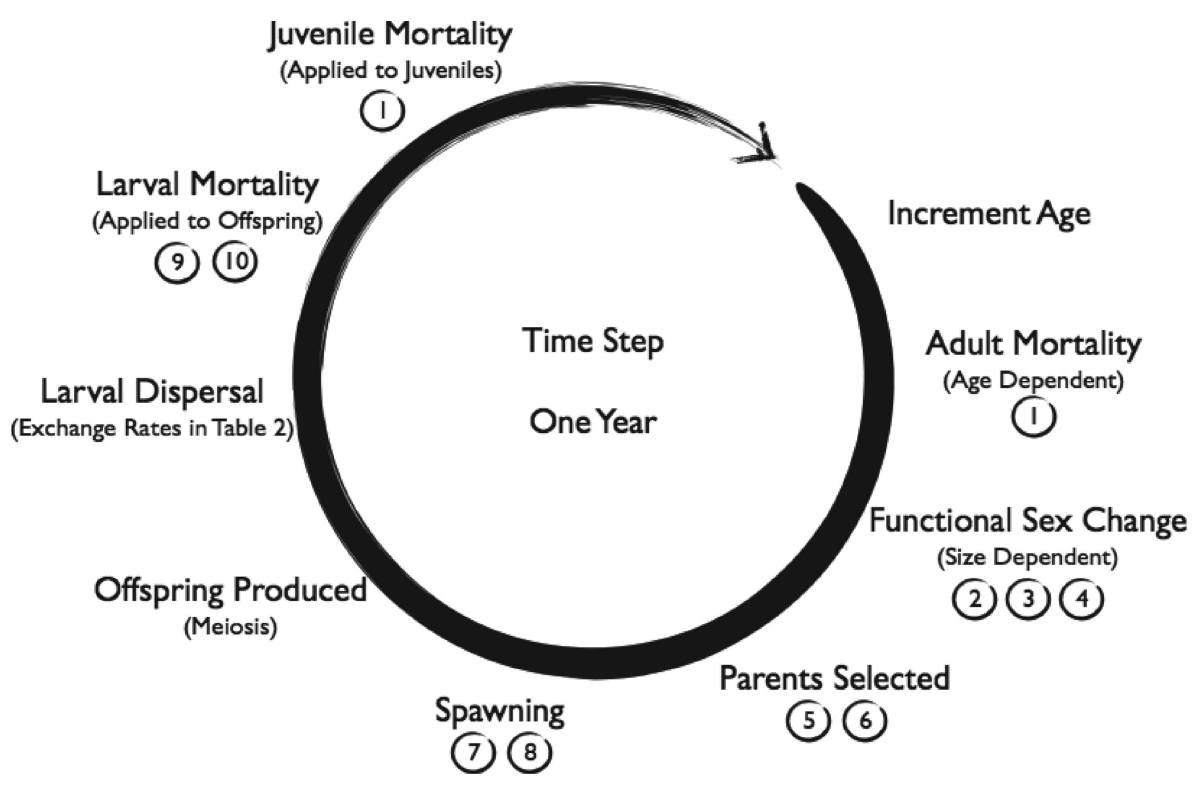

Figure 2. Model Schematic of processes executed in a single time step (one year). Numbered circles below each process indicates the equations invoked in that process.

produced in each population can remain within the source population (self-recruitment) or disperse to any of the other populations based on transfer probabilities obtained from a hydrodynamic-larval coupled model employing Lagrangian (particle-tracking) software incorporating larval behavior (Narváez et al., this issue). Larvae are created from parent pairs via independent assortment of parental genotypes and each population is composed of multiple cohorts of a number of individuals. Biological information about age, sex, and genotype for each individual in the model is independently stored with each oyster having a genotype defined by 10 pairs of chromosomes (Wang et al., 1999, 2005), each with four genes and two alleles per gene. Thus, each animal is specified by 40 genes and 80 alleles and the genotypes permitted are $A A, A B$, and $B B$.

Figure 2 summarizes the model processes in each model time step (each time step represents one year). Each year, after incrementing the age of all individuals by one, adults undergo age-dependent mortality and the functional sex changes for some. Then potential parents are chosen and reproduction occurs. Genetic recombination is implemented during the formation of each new offspring by the random choice of a location on each chromosome pair for each parent and the genetic information is crossed over at this location. Gametes are formed through the process of meiosis and each set of haploid chromosomes is obtained by randomly choosing one strand from each pair of chromosomes. Finally, one gamete is chosen at random from each parent for each offspring. The fate of each offspring is controlled by random larval mortality at a rate set to permit establishment of a relatively 
stable population. Each simulated mating season creates a cohort of individuals and a single mating season occurs each year. For simplicity, simulations were run under the assumption that animals born in one year do not spawn in the same year, a reproductive pattern typical of all populations except those at the most southern extent of the species' range (Stauber, 1950; Hayes and Menzel, 1981; Kennedy and Krantz, 1982; Barber et al., 1991).

Many of the processes in the model depend on a random draw. Unless otherwise indicated, a number is drawn from a uniform distribution with a range from 0 to 1 . These uniform deviates $(R)$ are obtained from the pseudo-random generator function described by Press et al. (1986). Whenever a normal deviate $(N)$ is required, the gasdev routine of Press et al. (1986) is used to obtain a random deviate from a zero mean, unit variance normal distribution. Repeat simulations using different sequences of random numbers returned results with only modest variations in scale and trend in initial trials. Consequently, results are provided only for single simulations for each set of parameter values. The main model results are based on stochastic equilibrium values that are estimated after 100 generations; full simulation outputs are provided in Figure 3.

Two distinct historical periods representing temporal variability in metapopulation dynamics are used for model parameterization, allowing examination of the influence of regime shifts on the transfer of neutral alleles. The '2000s' is representative of the decade from 2000 through 2010 and is characterized by spatially variable oyster population mortality and abundance (discussed in detail below). In contrast, the '1970s' is an era from 1970 through 1979 during which population mortality and abundance were relatively similar spatially (discussed in detail below). A thorough history of the Delaware Bay oyster population and its fishery can be accessed in Ford (1997) and Powell et al. (2008).

The model has three basic components, (i) a post-settlement population dynamics submodel that contains parameterizations for growth, mortality and reproduction; (ii) a larval submodel that contains parameterizations for larval mortality, larval exchange, and early juvenile survival and (iii) a gene submodel that describes each individual in terms of its genetic structure. Additional details of the single population model structure and formulation, on which the metapopulation model is based, are described in Powell et al. (2011 b,c,d). Here, we recapitulate model processes pertinent to neutral allele behavior in this study, namely specification of the processes of growth, reproduction, and mortality. A schematic of the processes in each time step, with reference to the equations described below is shown in Figure 2.

Figure 3. Full simulation output for allele frequency over time for the neutral allele marker initiated in Population 1 (left column) through Population 4 (right column). Left panels in each plot show allele frequencies under differing larval dispersal simulations; right panels show allele frequencies under differing population dynamics simulations. The 2000s simulation is shown for reference in both panels (heavy black line). Plots from top to bottom show frequency of the neutral allele within Populations 1-4 respectively. 

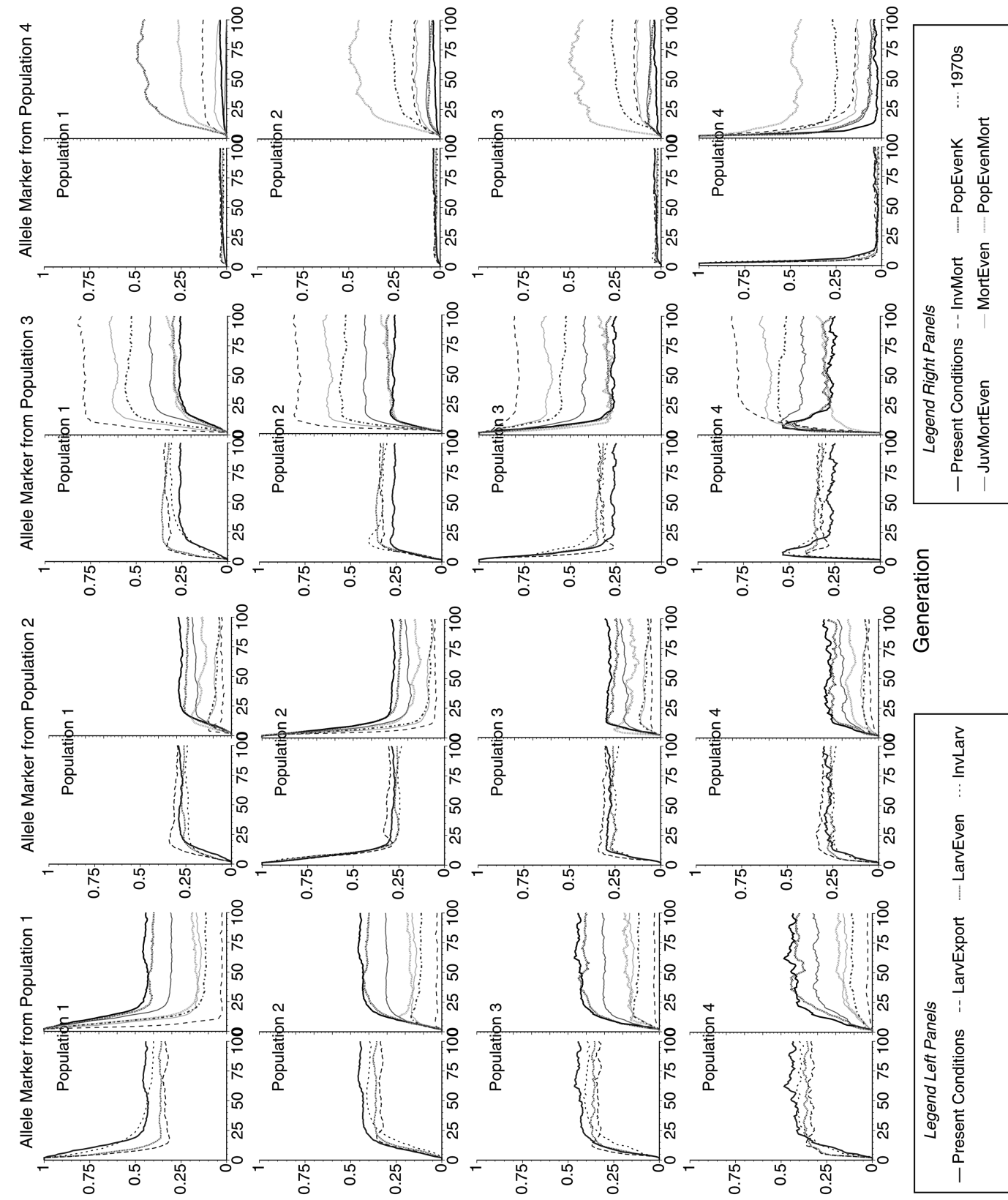

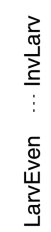

논

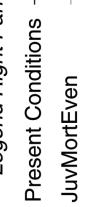

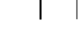


In the population dynamics submodel the probability of mortality is derived from the age of the animal such that:

$$
P_{\text {mort }}=0.5\left(1+\tanh \left(\frac{\text { Age }- \text { AveAgeMort }}{\text { AveSpreadMort }}\right)\right)
$$

where $P_{m o r t}$ is the probability of death and Age is age in years. $P_{\text {mort }}$ increases nonlinearly with Age such that the rate of increase is low at young and old Age and is greatest at AveAgeMort (the average age of mortality). AveSpreadMort controls the range of ages and how steeply mortality probability approaches 1 (see also Fig. 2 in Powell et al., 2011b). Juvenile mortality is specified separately as a specific rate applied to recruited animals of age 0 .

The sex of new recruits is determined by the $M F$ allele system described by Guo et al., (1998). $M F$ animals are permanent males. $F F$ animals are protandric males. Each generation, a protandric male is given the chance to convert to a functional female (protantdric males are present at $75 \%$ of the population following Guo et al., 1998). A conversion probability was obtained from empirical data from Delaware Bay (Powell et al., 2012a,b or c) using age-length relationships developed by Kraeuter et al. (2007). Powell et al. (2012a,b or c) found that the relationship between the fraction female, $F f$, and age could be modeled as a Gompertz curve:

$$
F f=\alpha e^{\beta e^{(\gamma \cdot A g e)}}
$$

where Age is the age of the animal in years. Eq. 2 can be used to estimate a probability for any animal changing from male to female based on its derivative:

$$
D f=\frac{d F f}{d A g e}=\alpha \beta \gamma e^{\left((\gamma \cdot A g e)+\left(\beta e^{(\gamma \cdot A g e)}\right)\right)}
$$

The probability is then calculated as:

$$
P_{\operatorname{sex} \Delta}=\min \left(1, \frac{D f}{1-F f}\right) .
$$

For the simulations used here, the parameter values for $\alpha, \beta$ and $\gamma$ are population-specific; values are provided in Table 2. Due to the age dependency of the probability of sex change, all long-lived protandric individuals eventually become functional females. As all oysters that are protandric begin life as male, all recruits are male. However, some recruits convert to female prior to first spawning, as appears to be the case in populations from Delaware Bay (Powell et al., 2012c).

The fraction of the population parenting each generation is derived from a predefined fraction of parents reproducing each mating season (FracParents set at $0.05 \%$ annually), based on estimates of effective population number for oysters in Delaware Bay (Hedgecock et al., 1992; Hedgecock, 1994):

$$
\text { FrParents }=\text { FracParents } \cdot 10^{(\text {N.FracParentsVar })}
$$


FracParentsVar permits variability to exist in the fraction of parents reproducing. FrParents is used to determine the number of parental pairs as:

$$
n \text { Parents }=\max (0.5 \cdot \text { FrParents } \cdot \text { LastAnimal, minParent })
$$

where LastAnimal is the count of adult animals in the population. A minimal number of parents, minParents, is allowed to reproduce, thus guaranteeing some, albeit low, level of reproduction when abundance becomes low.

Potential parents are drawn randomly, without replacement, from a list of all animals. Drawing stops when enough males and females accrue to provide $n$ Parents, or until the list of animals is exhausted. Each pair of parents, taken randomly, without replacement, from the parents' list, produces a number of offspring up to a maximun set at the beginning of the simulation. The number of offspring produced is affected by parental age through a weightbased Von Bertalanffy process (Fabens, 1965; Jensen, 1997) relating size and fecundity to age:

$$
W=W_{\infty}\left(1-e^{-k\left(A g e-A g e_{0}\right)}\right)^{b}
$$

where Age is age in years, $A g e_{o}, k$ and $L_{\infty}$ are the population-specific von-Bertalanffy parameters (values provided in Table 2) and $W_{\infty}$ is obtained from $L_{\infty}$ using the allometric equation $\mathrm{W}=\mathrm{aL}^{\mathrm{b}}$ with $\mathrm{a}=0.0003$ and $\mathrm{b}=2$. Note that for oysters, weight scales more nearly with the square of length rather than the cube (Yoo and Yoo, 1973; Powell and Stanton, 1985).

Eq. 7 is applied to fecundity by assuming that oyster spawn is a standard fraction of biomass (Hofmann et al., 1992, 1994). The number of offspring (nOff) produced by a female of a given age $A g e$ and weight $W$ is:

$$
n O f f=\frac{W_{\infty}}{W_{76}}\left(1-e^{-k\left(\text { Age }- \text { Age }_{0}\right)}\right)^{b} \operatorname{MaxOff}
$$

where MaxOff is the fecundity for a 76-mm oyster [scaled to maximum of 100,000 for all simulations for computational efficiency; note that for oysters, the fecundity of a 76-mm oyster can reach 60 million eggs (Davis and Chanley, 1955)]. Genotypes of the offspring are determined by random combination of haploid genotypes from each parent after meiosis. Crossing over of genetic information is permitted during meiosis.

In the larval submodel, all offspring produced are transferred among the populations in the metapopulation following a transfer probability obtained from a Lagrangian individualbased model that simulates larval exchange in Delaware Bay (Narváez et al., this issue). The Lagrangian model used a coupled physical circulation model [the Regional Ocean Modeling System - ROMS (Haidvogel et al., 2000; Shchepetkin and McWilliams, 2005)] and oyster larval model that simulated larval growth and vertical migratory behaviour (Dekshenieks et al., 1993, 1996, 1997; Narváez et al., this issue). The physical circulation model (ROMS) is a 3-dimensional hydrodynamic circulation model (horizontal resolution ranges from 0.2$2.1 \mathrm{~km}$, vertical resolution ranges from $0.03-6.2 \mathrm{~m}$ ) that uses freshwater, air-sea and tidal 
forcing and has been configured and calibrated for Delaware Bay (Wang et al., this issue). The larval growth model estimates larval growth as a function of temperature, salinity, food supply and turbidity and was parameterized using laboratory and observational studies (Dekshenieks et al., 1993; Narváez et al., this issue). Larval vertical migratory behavior depends on salinity (controls time swimming), temperature (controls swimming speed) and larval size (controls swimming and sinking speed) (Dekshenieks et al., 1996; Narváez et al., this issue).

Larval movement in the estuary is determined by passive movement in the horizontal; vertical position is determined by vertical flow velocity, turbulence, and larval behavior. Larval transfer rates used here were extracted from the connectivity matrix developed by Narváez et al. (this issue; Populations 1-4 correspond to HOP, ARN, SHR, and BEN respectively in their figure 7e), by scaling the larval connectivity values among the four populations to $100 \%$. By scaling larval transfer rates to $100 \%$, advective larval loss is neglected. To adjust for this, sufficient larval mortality (Eq. 10) is applied to account for both larval loss due to mortality in the plankton and advective loss.

A random selection of larvae is sent to each destination population whether local (selfrecruiting) or immigrated, as determined by the transfer probability matrix. These larvae survive with a probability:

$$
\text { LarvSurv }=(0.5+1.5 R) \frac{K}{n \text { Off nParents }}
$$

where $R$ is a random draw, $n$ Parents is the number of parents in the population and local carrying capacity $(K)$ regulates the number of animals in the population. This relationship incorporates the logistic process in which average recruitment per adult declines as population abundance increases with respect to the local carrying capacity. The ability of oysters to filter water more rapidly than food is re-supplied, thus generating a food limitation (Wilson-Ormond et al., 1997; see also Powell et al., this issue), provides a theoretical basis for this expectation. The probability of death for each individual larva is:

$$
P=1-\text { LarvSurv }
$$

If a random draw $R<P$, then the larva dies. If the larva survives to recruit into the destination population, it is given an identifying number, a birth date and an age of zero.

\section{b. Simulations}

Gene transfer among the populations was observed by initializing the model with $100 \%$ of the individuals in one population homozygous $B B$ at a particular locus, while the initial individuals in the remaining three populations were initiated homozygous $A A$ at the same locus (thus, there are no heterozygotes initially for that particular locus). As an example, for Population 1, all individuals in that population were initially homozygous $B B$ at locus 1 meaning that the only individuals with a $B$ allele at that locus at time zero are from Population 1. This allele frequency was initialized at a unique locus for each of the four 


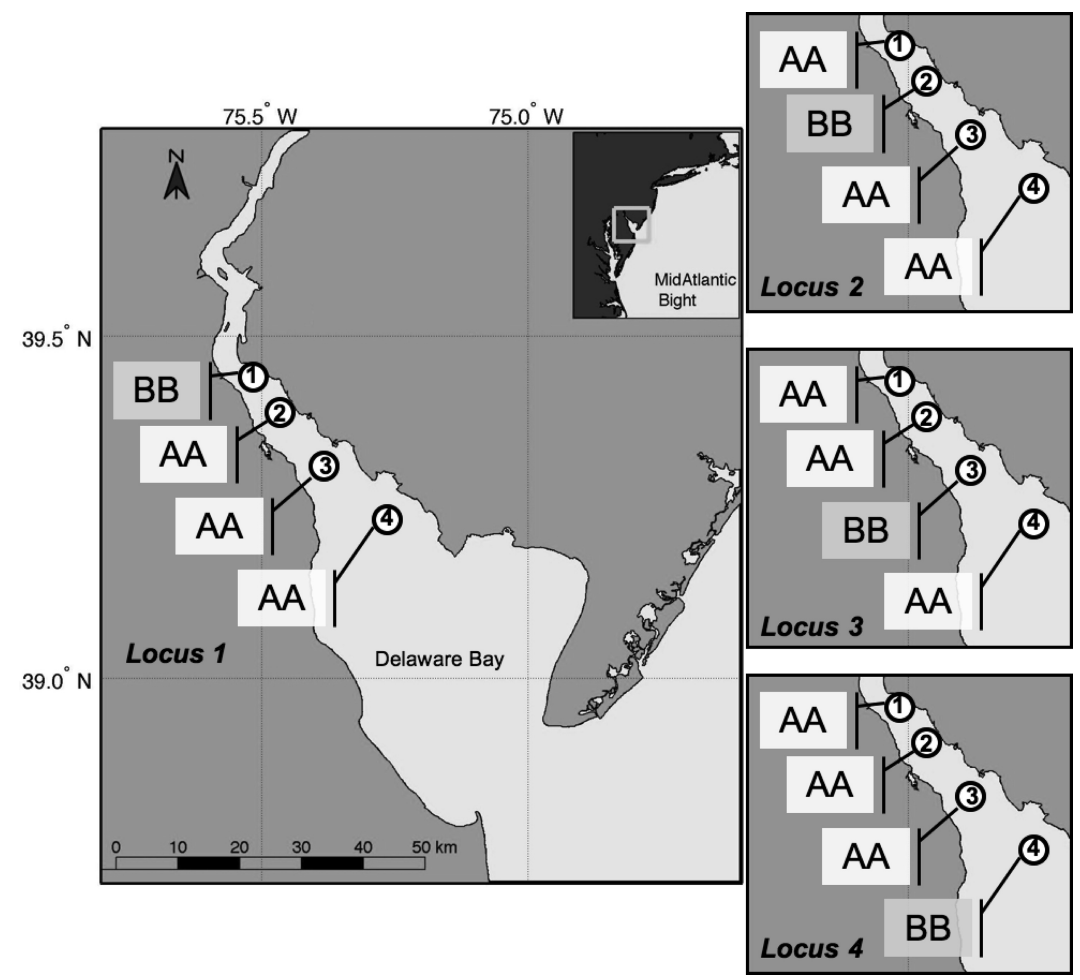

Figure 4. Cartoon showing the allele initiation set-up. The main map (left) shows the allele set-up for locus 1 in which Population 1 is homozygous BB and the remaining populations are homozygous AA. The insets at right show the initiation for the remaining 3 loci in which Populations 2-4 are initiated homozygous $\mathrm{BB}$ at each of the corresponding loci.

populations (Fig. 4). This allowed tracking of allele frequencies of the $B$-allele to follow the movement of neutral alleles from one population through the metapopulation over time. A series of simulations were conducted, the first two representative of the two eras in Delaware Bay (2000s and 1970s), followed by a sensitivity analysis series in which larval dispersal or local population traits were manipulated to test the influence of larval dispersal and local population dynamics on movement of neutral alleles within the metapopulation. A summary of simulation names and scenario details are provided in Table 1.

i. 2000s. Reliable and extensive empirical data are required to ensure model validity (Cowen and Sponaugle, 2009). Delaware Bay oyster stock assessments from 2000-2010 provided us with comprehensive data to define population parameters (Powell et al., 2009a, b; 2011a). The four simulated populations in our model correspond to the four Delaware Bay populations referred to in stock assessments as the very-low-mortality (1), low-mortality (2), medium-mortality (3) and high-mortality (4) populations (Powell et al., 2011a). Population characteristics for each of the four populations for the decade of the 2000s are shown in 
Table 1. Simulation names and details for each simulation.

\begin{tabular}{|c|c|c|c|}
\hline Sensitivity & Case & Population Scenario & Larval Dispersal Scenario \\
\hline & $2000 \mathrm{~s}$ & $\begin{array}{l}\text { As observed in Delaware Bay } \\
\text { for period 2000-2010. }\end{array}$ & $\begin{array}{l}\text { As predicted for } 2000 \text { s by } \\
\text { bio-physical model* }\end{array}$ \\
\hline & $1970 \mathrm{~s}$ & $\begin{array}{l}\text { As observed in Delaware Bay } \\
\text { for 1970's. Population } \\
\text { abundances and mortality } \\
\text { rates relatively even among } \\
\text { populations. }\end{array}$ & $\begin{array}{l}\text { As predicted for } 2000 \text { s by } \\
\text { bio-physical model* }\end{array}$ \\
\hline \multirow{3}{*}{ 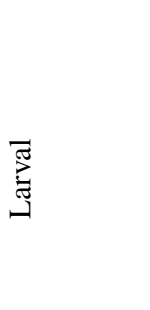 } & LarvExport & $\begin{array}{l}\text { As observed in Delaware Bay for } \\
\text { period 2000-2010. }\end{array}$ & $\begin{array}{l}\text { No self-recruitment, all larvae } \\
\text { transferred to destination } \\
\text { population evenly. }\end{array}$ \\
\hline & LarvEven & $\begin{array}{l}\text { As observed in Delaware Bay } \\
\text { for period 2000-2010. }\end{array}$ & $\begin{array}{l}\text { Even dispersal }(25 \%) \text { to:from } \\
\text { each population. }\end{array}$ \\
\hline & InvLarv & $\begin{array}{l}\text { As observed in Delaware Bay for } \\
\text { period 2000-2010. }\end{array}$ & $\begin{array}{l}\text { Inverse of predicted larval } \\
\text { dispersal rates. }\end{array}$ \\
\hline \multirow{3}{*}{ 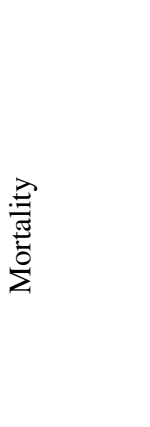 } & InvMort & $\begin{array}{l}\text { Observed } 2000-2010 \text { mortality } \\
\text { gradient reversed (upbay with } \\
\text { highest mortality, downbay } \\
\text { with lowest) }\end{array}$ & $\begin{array}{l}\text { As predicted for } 2000 \text { s by } \\
\text { bio-physical model* }\end{array}$ \\
\hline & MortEven & $\begin{array}{l}\text { No gradient in mortality, all } \\
\text { populations have same } \\
\text { mortality rate. }\end{array}$ & $\begin{array}{l}\text { As predicted for } 2000 \text { s by } \\
\text { bio-physical model* }\end{array}$ \\
\hline & JuvMortEven & $\begin{array}{l}\text { No gradient in juvenile mortality } \\
\text { (100\% juvenile survival for } \\
\text { all populations). }\end{array}$ & $\begin{array}{l}\text { As predicted for } 2000 \text { 's by } \\
\text { bio-physical model* }\end{array}$ \\
\hline \multirow{2}{*}{ 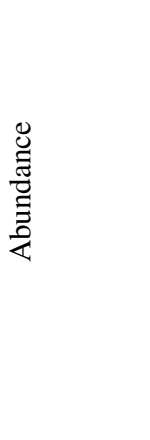 } & PopEvenK & $\begin{array}{l}\text { No gradient in population } \\
\text { abundance. Mortality } \\
\text { gradient as in } 2000 \text { s. Even } \\
\text { population abundance } \\
\text { achieved by density } \\
\text { dependant recruitment. }\end{array}$ & $\begin{array}{l}\text { As predicted for } 2000 \text { s by } \\
\text { bio-physical model* }\end{array}$ \\
\hline & PopEvenMort & $\begin{array}{l}\text { No gradient in population } \\
\text { abundance. Even abundances } \\
\text { achieved by increased or } \\
\text { decreased local adult } \\
\text { mortality rates }\end{array}$ & $\begin{array}{l}\text { As predicted for } 2000 \text { s by } \\
\text { bio-physical model* }\end{array}$ \\
\hline
\end{tabular}

*summarized from Figure 7e connectivity matrix in Narváez et al., this issue. 


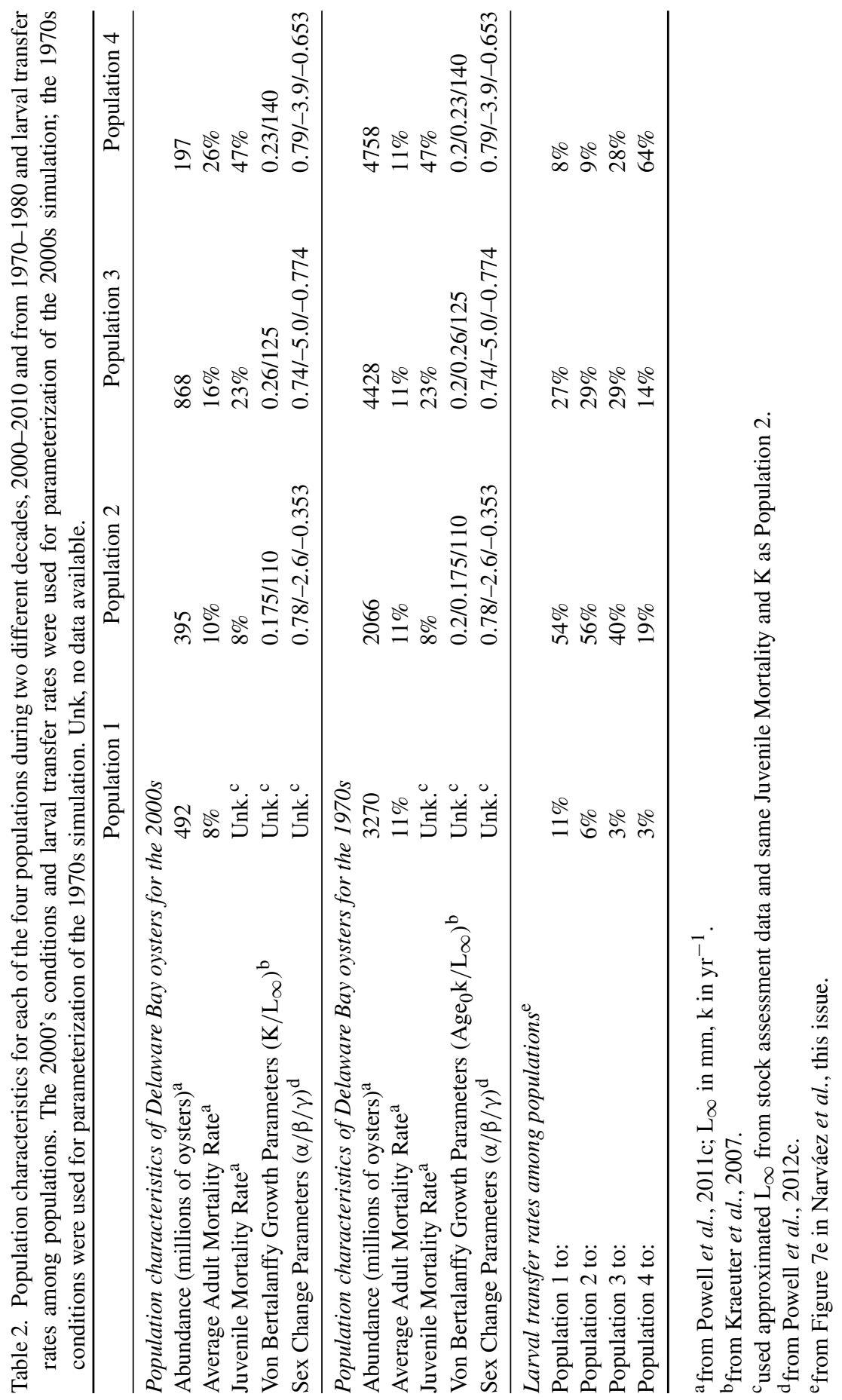


Table 2. Important differences among the four populations include a strong gradient in mortality from lowest mortality in the upestuary population (Population 1) to highest mortality in the downestuary population (Population 4), a gradient in growth rates with slower growth and smaller maximum size upestuary and higher growth and larger maximum size downestuary (Kraeuter et al., 2007), and an uneven population distribution with Population 3 containing nearly half of the individuals in the overall metapopulation, a condition that has existed for most years since 1985 (Powell et al., 2009a). The gradient in adult mortality derives from differential mortality due to Dermo (Perkinsus marinus) disease (Ford and Tripp, 1996) and a parallel gradient in juvenile mortality due to predation (Powell et al., 2011a).

A simulation of 2000s conditions was run in which the four simulated populations had characteristics that reflected the Delaware Bay populations between 2000-2010 (described above). Larval transfer rates among populations used in this simulation are listed in Table 2, and were derived from Narváez et al. (this issue, their Fig. 7e). Von Bertalanffy growth rates, probabilities of juvenile and adult mortality, and carrying capacity are specified for each population independently as outlined in Table 2 .

ii. 1970s. A simulation was run in which mortality rates and abundances of the 1970's were used (1970s). Data from annual stock assessment of oysters in Delaware Bay (Powell et al., 2009a,b; 2011a) document that local population abundances and mortality rates for the four simulated populations during the 1970s differed from that of the 2000s. Both the abundances and mortality rates of the four populations were relatively even among all four populations during a period from circa-1970 to 1985 in contrast to the strong upestuarydownestuary gradient in mortality and biased abundance favoring the medium-mortality region (Population 3) that exists today and that existed prior to 1970 (Table 2).

iii. Larval dispersal. A sensitivity analysis was performed by carrying out a series of simulations in which variations in larval transfer rates were used to test the influence of changes in larval dispersal on movement of a neutral allele among the four populations. Larval dispersal simulations included (1) a simulation in which populations did not self-recruit and transferred all larvae evenly to the other three populations (LarvExport), (2) a simulation in which all populations dispersed larvae evenly among all four populations (25\% self-recruitment) (LarvEven) and (3) a simulation in which larval transfer rates of Populations 1 and 4 and Populations 2 and 3 were swapped to invert the relationship defined by the connectivity matrix obtained from the larval-physical model run under 2000s conditions (InvLarv).

iv. Mortality. A sensitivity analysis was performed by carrying out a series of simulations designed to test the influence of differential mortality rates among the populations on movement of a neutral allele. Mortality simulations included a scenario in which (1) all four populations experienced the same adult mortality rate (MortEven), (2) the adult mortality gradient that existed in the 2000s was reversed (InvMort), and (3) juvenile mortality was equivalent among populations (JuvMortEven).

v. Abundance. Two additional sensitivity simulations were run to test the influence of changing population abundances on movement of a neutral allele. The population abundance 


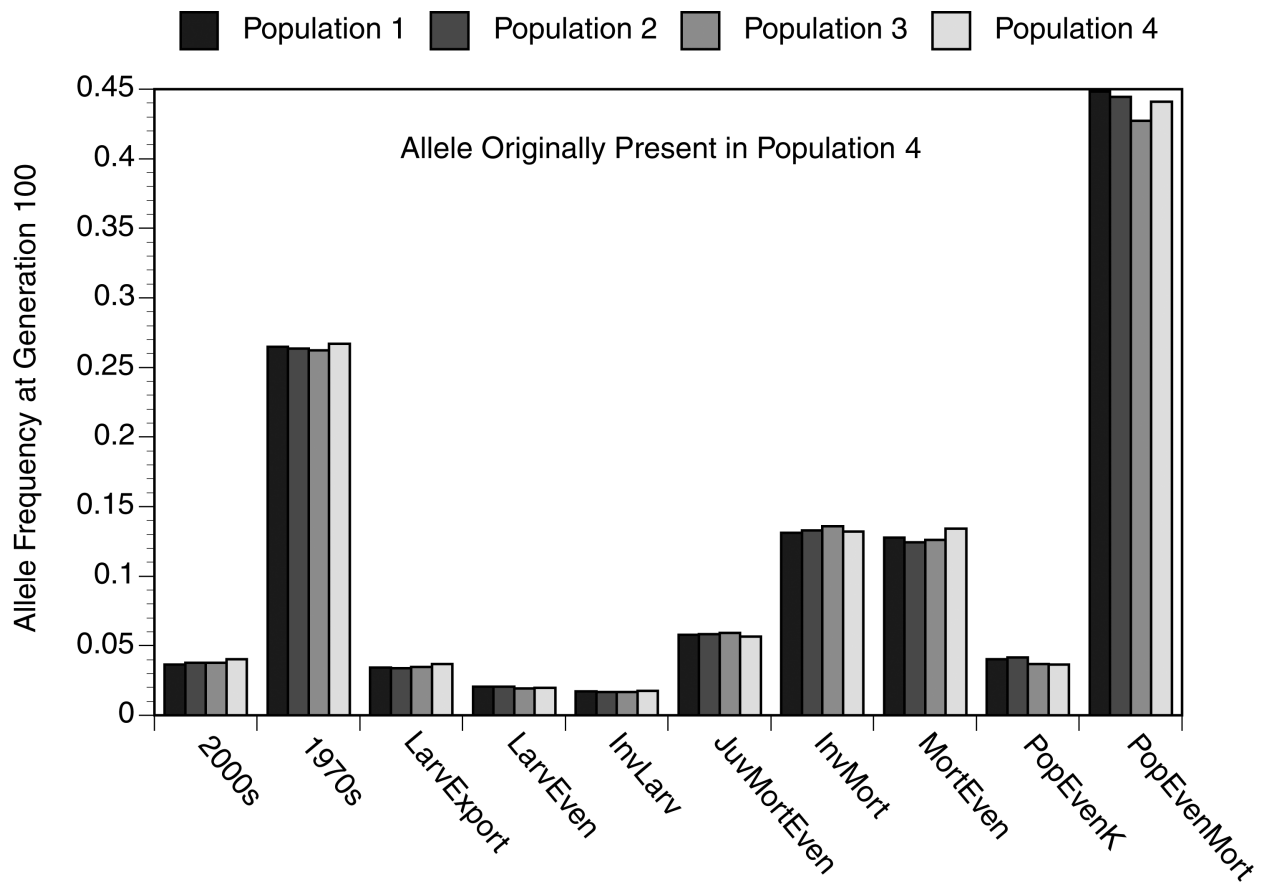

Figure 5. Simulated frequency of the neutral allele marker initiated in Population 4 for each population. Bars from black to light grey show frequency of the neutral allele within Populations 1-4 respectively.

scenarios included one that created even population abundances by density-dependant effects on local carrying capacity $(K)$. In this case, recruitment into the population varied as a compensatory function of population abundance at the time of recruitment (PopEvenK). The second population abundance simulation achieved even abundances by increased or decreased local adult mortality rates (PopEvenMort).

\section{Results}

a. $2000 \mathrm{~s}$

Simulations replicating the 2000-2010 population dynamics and larval dispersal in Delaware Bay showed limited transfer of neutral alleles from Population 4 to the remaining populations in Delaware Bay (column 4 in Fig. 3, left bars Fig. 5). Complete mixing should produce a metapopulation $B$-allele frequency of $50 \%$. Rather than this outcome, over 100 generations, allele frequency for the $B$-allele in the overall metapopulation dropped by $4 \%$ relative to the initial condition (initial metapopulation $B$-allele frequency is equal to the proportion of initial animals in the originating population). Final allele frequency was $4 \%$, much below the equilibrium expectation of $50 \%$ (Figs. 5,7). 


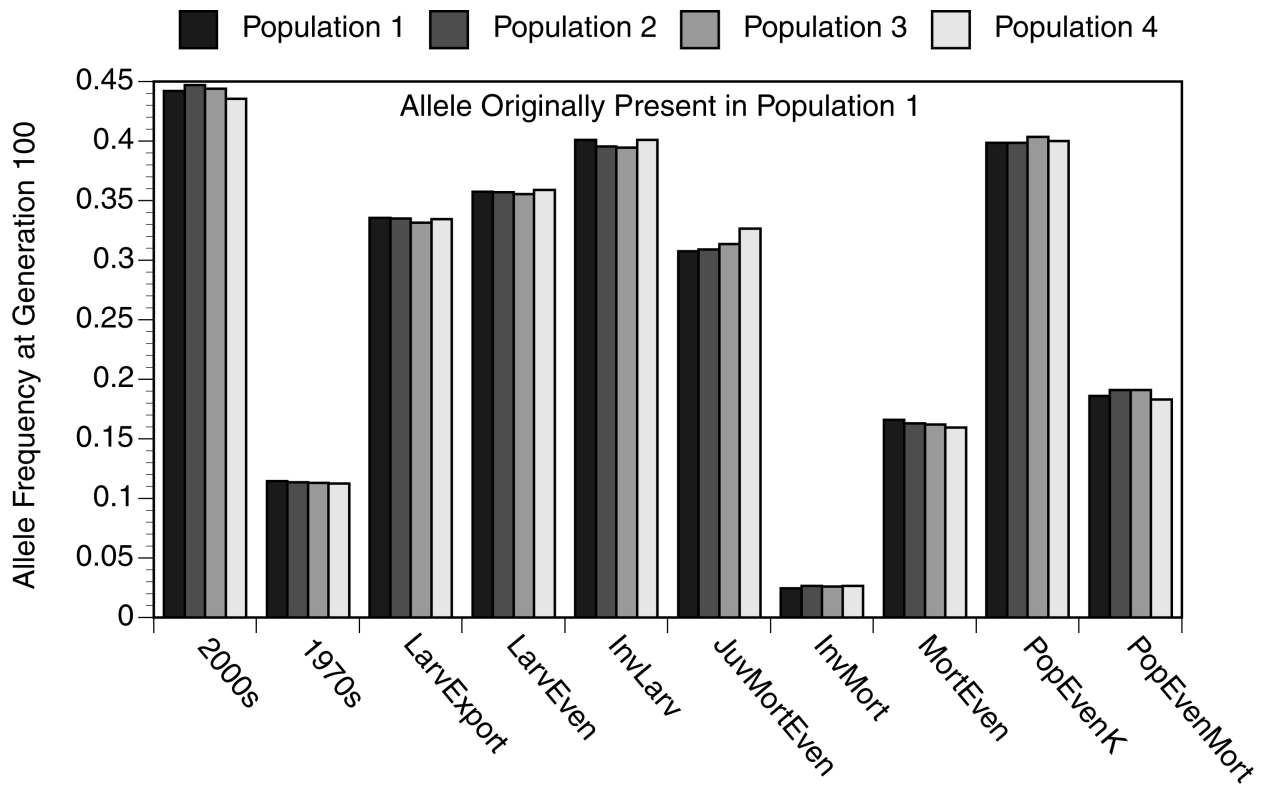

Figure 6. Simulated frequency of the neutral allele marker initiated in Population 1 for each population. Bars from black to light grey show frequency of the neutral allele within Populations 1-4 respectively.

Alleles initially present in the other three populations were propagated throughout the bay with greater efficiency (example Fig. 3,6 ); in no case did the frequency of the $B$-allele reach $50 \%$. However, the $B$-allele frequency neared this value (44\%) when the allele was initially present in Population 1, farthest upestuary (Fig. 6). In all cases, a relatively stable allele frequency was achieved in the first 20 years of simulation (Fig. 3).

\section{b. 1970 s}

Population abundance in Delaware Bay during the 1970s was more evenly distributed between the four populations than today and adult mortality rates were similar among populations in contrast to the strong downestuary gradient of the 2000s (Table 2). Thus, the 1970s simulation effectively combined changes in two population dynamics parameters (abundance and mortality rate). The $B$-allele being originally present in Population 4 resulted in a higher exchange of neutral alleles among populations than the 2000s case (Fig. 5) and a 19\% increase in metapopulation allele frequency (Fig. 7). The 1970s case diverges strongly from the 2000s case in the remaining three populations also (example Fig. 6). For the case in which the $B$-allele initially was present in Population 3, the final metapopulation allele frequency in the 1970 s case was $27 \%$ greater than that achieved for the 2000s case. When the marker was initially present in Population 1 or Population 2, the 1970 s case led to a final metapopulation allele frequency that was $33 \%$ and $22 \%$ lower than the 2000s case respectively (Fig. 7). 


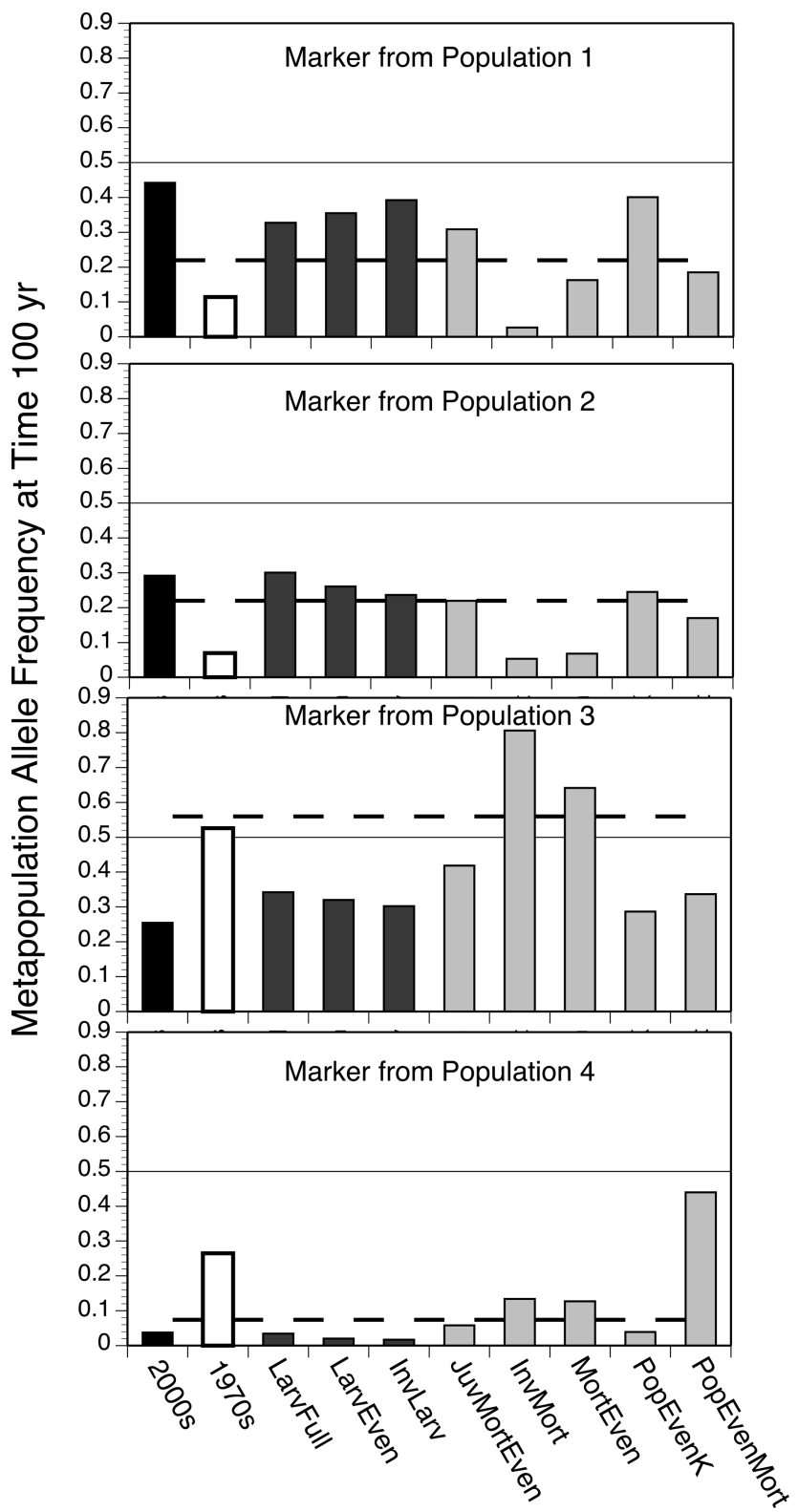

Figure 7. Change in simulated metapopulation allele frequency (the frequency of the neutral B-allele originally fixed in a given population, but absent from the remaining) for each of the four populations (top to bottom panel is Population 1 through Population 4) over the duration of the simulation. Black bar indicates the 2000s case, white bar shows the 1970s case, dark grey bars indicate the altered larval dispersal simulations and light grey bars indicate simulations altering population dynamics. 


\section{c. Larval dispersal}

Changes in larval dispersal among populations failed to show large changes in genetic connectivity among populations relative to the 2000s simulation (left panels Fig. 3, Figs. 5, 6, dark grey bars Fig. 7). Interestingly, reversal of larval exchange from that predicted by the larval-physical model (InvLarv), also failed to result in notable changes in transfer of neutral alleles from the initial populations to the remaining populations. When the $B$-allele was initially present in Population 4 , Allele frequency in the metapopulation dropped over 100 generations for all simulations using an alternate larval dispersal scenario (Fig. 5) and in no case did the final $B$-allele frequency in the metapopulation reach $5 \%$ (Fig. 7).

\section{d. Mortality}

Elimination of the juvenile and adult mortality gradients among populations and inversion of the mortality gradient present in the 2000 s so that mortality rate increased upestuary all led to large changes in allele frequency of the neutral allele in destination populations compared to the allele frequency observed in the 2000s case (Figs. 5,6,7). When the $B$-allele was initially present in Population 4, farthest downestuary, an overall increase in metapopulation allele frequency of this allele was observed in two mortality cases (InvMort, MortEven) (Fig. 5,7); metapopulation $B$-allele frequency rose to near $10 \%$ in these two cases. When the $B$-allele was initially present in Population 3 , an increase in metapopulation allele frequency was again observed in two mortality cases (InvMort, MortEven) (Fig. 7); metapopulation $B$-allele frequency rose to over $60 \%$ in these two cases. By contrast, when the $B$-allele was initially present in one of the two upestuary populations, the influence of modifications to the mortality gradient was to reduce the frequency of the $B$-allele (Fig. 6,7); thus a dichotomous outcome became apparent, with the tendency for the $B$-allele frequency to be enhanced by changes in the mortality gradient when initially present downestuary countered by the tendency for the $B$-allele frequency to be reduced by changes in the mortality gradient when initially present upestuary.

\section{e. Abundance}

Elimination of the inequality in population abundance amongst the four populations typical of the 2000s by adjusting mortality (PopEvenMort) led to a large change in transfer of the neutral allele within the metapopulation (Figs. 5,6,7); the final $B$-allele frequency increased by $40 \%$ for the marker from Population 4 and decreased by $4 \%$ for the marker from Population 1. The opposite was observed for the case of even population abundance obtained via compensatory recruitment to establish carrying capacity (PopEvenK) (Fig. 7). Thus, changes in the abundance between populations affected allele frequency relative to the 2000s simulation when mortality was the agent used, but not if carrying capacity (via compensatory recruitment) was the agent used. 


\section{Discussion}

\section{a. Dynamics of allele export and retention}

We observed a large difference in neutral allele transfer in a metapopulation when abundance and mortality differed between individual populations, whilst changes in larval dispersal were not effective in altering genetic connectivity. Although larval dispersal in a sessile marine population is the mechanism for gene transfer among populations, these simulations highlight the importance of dynamics and characteristics of individual adult populations in determining the flow of neutral alleles within a metapopulation. In particular, betweenpopulation differences in adult mortality rate among populations, which determine adult generation time and ultimately local population abundance, appear to exert a controlling influence on the dispersal of alleles.

These results agree with other researchers who suggest that larval dispersal does not necessitate gene flow; dispersal may not translate to gene flow if migrants fail to reproduce (Bohonak, 1999; Pineda et al., 2007; Hedgecock et al., 2007). The concept of 'reproductive population connectivity' (Pineda et al., 2007) states that connectivity is dependent on dispersal in partnership with survival to reproduction. They argue that consideration of population connectivity by definition must include larval dispersal, but should not fail to include other factors that influence post-recruitment survival and survival to reproduction. Our results suggest that this concept is particularly true when considering population genetic connectivity and that differential adult mortality rates among populations may be of much greater importance, at least in sessile marine species like oysters, than previously considered.

The simulations point to the influence of two processes that dictate the efficiency of genotype propagation to and retention in local populations. One of these is annual genotype export potential, in which one population may provide to the metapopulation a disproportionate number of larvae at a given time (Swearer et al., 2002; Guo et al., 2005; Hellberg, 2009). The export potential in a given year is determined by the abundance of parents in the population and the local mortality rate. Second, retention of a genotype in a population relies on the replication potential within the population for that genotype, which depends on the generation time, a function of fecundity over the life span of the cohort (Deevey, 1947). The replication potential therefore depends on local mortality rate, which determines local average life span. Thus these two processes rely on local abundance and mortality, with mortality playing an important role because it simultaneously restricts generation time, and thereby the replication potential of the genotype, and also the number of individuals in the population, and hence the yearly export potential of the genotype. Populations with a high natural mortality rate will have limited replication potential and limited export potential and are more likely to be sinks for the immigrant genotypes.

\section{b. Source versus sink in the metapopulation}

We can now compare the capabilities of the four populations as sources and sinks of genotypes. Population 4, the most downestuary population, during the 2000s is a sink (Fig. 7). 
Genotype production and export is low because abundance is low. Replication potential is low, so that genotype retention within the metapopulation is compromised. Both are products of the high mortality rate as larval retention rate is high (Table 2). High growth rates and large size that increase fecundity at age are poor counterweights to the impact of mortality on population genotype retention. As a consequence, Population 4 tends to reflect the genotypes of the upestuary populations that continuously pump alleles into the population. During the 2000's, oyster populations in the high-salinity areas (downestuary) of Delaware Bay can be expected to be of this type as elevated mortality due to oyster disease such as Dermo simultaneously limits generation time and abundance in these areas (Powell et al., 2011d).

In contrast, Population 3, some distance upestuary, is a source (Fig. 7). Although mortality rates remain moderately high, abundance is high causing genotype production to remain high. In addition, growth rate and maximum size are higher than upestuary populations, thus fecundity at age is enhanced. Life span is long relative to Population 4, thus replication potential is improved. Finally, higher larval transfer rates permit alleles from this population to rapidly populate upestuary and downestuary regions.

Contrast the 2000s case to that of the 1970s. In the 1970s case, a relaxation of mortality rates and, consequently, an evening of abundance, permits Population 4 to adopt characteristics of a source. Estuary-wide export of alleles is enhanced, though not to the extent of Population 3 that also benefits from lower mortality, while retaining the higher transfer capacity provided by the estuary's hydrodynamics. These outcomes are anticipated from the change in mortality rate between the 2000s and 1970s. What is surprising is the effect of 1970s conditions upestuary of Population 3, as the mortality rate is not much altered between the two time periods. In both upestuary populations, the ability of the population to retain the $B$-allele, if originally present, and the ability to export the $B$-allele to other populations is muted. Presumably, this is due to the enhanced export capacity of Populations 3 and 4 . Thus, the contrast of the 1970s and 2000s would appear to be one of a change in the locations of sources and sinks.

\section{c. The influence of regime shifts and MPAs}

Differences between the simulations for the 2000s and the 1970's illustrate that population and genetic connectivity are dynamic and may change fundamentally between regimes. Regime shifts are of recognized importance in marine populations (Collie et al., 2004; Rothschild and Shannon, 2004) and Delaware Bay oyster populations are no exception (Powell et al., 2009a,c). In this case, the 1970s were a period of high abundance separated from today by a regime shift that occurred in 1985-86 when abundance declined by about a factor of five. Our model suggests that the mechanisms of gene flow and genotype retention among the Delaware Bay oyster populations were substantively changed by this event. This temporal variability has potential consequences for development of disease resistance within the metapopulation through the regulation of the export of alleles conferring disease resistance from populations undergoing selection and the potential of such populations 
to support sufficient replication potential for local retention of the selected alleles. This temporal variability also has potential consequences for adaptation to climate change, such that conditions in the 1970s may have allowed better mixing of neutral alleles encouraging equivalent adaptive capacity throughout the metapopulation within Delaware Bay if those neutral alleles were to later become beneficial. Our results suggest that in Delaware Bay, differential mortality (a condition necessary for selection) and upestuary transfer of genes are mutually exclusive.

Populations with lower mortality rates relative to other populations in a metapopulation may gain advantage in transfer of neutral alleles by having more older, and in the case of oysters, bigger and more fecund animals than high-mortality populations. Greater population fecundity would allow those populations to effectively swamp the neutral allele contribution from other populations and thereby maintain a higher relative genetic contribution to the metapopulation. This suggests that creation of Marine Protected Areas (MPA) within or adjacent to areas of high fishing may have metapopulation genetic implications from the strong mortality differential generated between the MPA and nearby populations. Katsanevakis (2009) used a matrix modeling approach to show that large differentials in mortality rates between bivalve populations, created by fishing pressure on one population and inaccessibility of the fishery to adjacent populations, had a large influence on population dynamics. The results described here indicate that these differences in population dynamics could strongly affect genetic connectivity among these populations, in agreement with predictions derived from mathematical models of source-sink population genetics by Gaggiotti (1994).

In marine species with larval stages, the pelagic larval duration is believed to be a good predictor of dispersal (Bohonak, 1999; Shanks et al., 2003; Siegel et al., 2003; Lester and Ruttenberg, 2005; Shanks, 2009). If this is true, it is expected that pelagic larval dispersal should also correlate well with population genetic connectivity given that dispersal is the mechanism for gene flow among populations (Weersing and Toonen, 2009). A meta-analysis of the relationship between pelagic larval dispersal and FST (a commonly used measure of population genetic differentiation (Wright, 1951)) for 130 species showed only a weak correlation (Weersing and Toonen, 2009). The authors note that this unexpected result could derive from high uncertainty in estimates of both larval dispersal and FST (Weersing and Toonen, 2009). Simulation results described here suggest that further error would be introduced into the correlation between pelagic larval dispersal and FST through differential mortality and abundances among populations and inclusion of these population dynamics parameters should help explain variability in genetic connectivity relative to dispersal.

\section{d. Model caveats}

The simulations attempt to represent a complex biological process, namely genetic connectivity in a metapopulation. As with any modeling exercise, a trade-off exists between realism and model simplicity. Consequently certain processes and drivers are not included either because their relationship with other components is inadequately understood or to simplify the model. In this model, we do not include environmental drivers explicitly although 
environmental changes (differences in salinity and temperature, for example) are known to influence dispersal (Narváez et al., this issue) and local mortality rates (Gunter, 1955, Soletchnik et al., 2007, Powell et al., 2008). Rather than including these environmental drivers, the model uses interannual stochasticity through reliance of model processes on a random draw and differential parameterization of simulations to vary population dynamics consistent with a known range of environmental conditions. Additionally, it is important to recognize that the outputs discussed here use neutral alleles only and thus selection does not play a role in determining the simulated allele frequencies.

\section{Conclusions}

Recently, incorporation of dispersal and population genetics has been a priority in ecosystem models. However, many of these models use fixed population size and/or uniform mortality (Landguth and Cushman, 2010; Rivera et al., 2011). Results of simulations conducted in the present study indicate that holding population size and mortality constant may fail to represent important factors that influence movement of neutral alleles. Our results suggest that differential adult mortality rates and an inequality in abundance among populations exert strong influence on dispersal of neutral alleles and that connectivity and gene flow is temporally dynamic. Bearing this in mind, it is essential to consider differential population dynamics such as mortality and abundance in the management of marine metapopulations and to recognize the ability of regime shifts to foster differential gene flow between the constituent populations.

Acknowledgments. Sincere thanks to all Haskin Shellfish Research Laboratory staff, NJDEP and Delaware Bay Oystermen who work diligently and co-operatively each year to provide reliable annual oyster population estimates in Delaware Bay. K. Ashton-Alcox provided valuable historic oyster data, D. Narváez provided critical insight on larval dynamics and P. López-Duarte gave a thoughtful review of this manuscript. Funding was provided by the National Science Foundation (OCE-6022642 and OCE-0622672) and by the Army Corps of Engineers under their Section 22 funding authority, contract \#W912BU-11-C-0004, through the Seaboard Fisheries Institute, in collaboration with the Sponsor, the South Jersey Port Corporation, a public agency of the State of New Jersey.

\section{REFERENCES}

Barber, B. J., S. E. Ford and R. N. Wargo. 1991. Genetic variation in the timing of gonadal maturation and spawning of the eastern oyster, Crassostrea virginica (Gmelin). Biol. Bull., 181, 216-224.

Bertness, M. D., S. D. Gaines and R. A. Wahle. 1996. Wind driven settlement patterns in the acorn barnacle Semibalanus balanoides. Mar. Ecol. Prog. Ser., 137, 103-110.

Bohonak, A. J. 1999. Dispersal, gene flow, and population structure. Quart. Rev. Biol., 74, 21-45.

Botsford, L. W., F. Micheli, and A. Hastings. 2003. Principles for the design of marine reserves. Ecol. App., 13, S25-S31.

Collie, J. S., K. Richardson and J. H. Steele. 2004. Regime shifts: can ecological theory illuminate the mechanisms? Prog. Oceanogr., 60, 281-302.

Connolly, S. R. and A. H. Baird. 2010. Estimating dispersal potential for marine larvae: dynamic models applied to scleractinian corals. Ecol., 91, 3572-3583. 
Cowen, R. K. and S. Sponaugle. 2009. Larval dispersal and marine population connectivity. Ann. Rev. Mar. Sci., 1, 443-466.

Davis, H. C. and P. E. Chanley. 1955. Spawning and egg production of oysters and clams. Proc. Natl. Shellfish. Ass., 46, 40-58.

Deevey, E. S. 1947. Life tables for natural populations of animals. Quart. Rev. Biol., 22, 283-314.

Dekshenieks, M. M., E. E. Hofmann, J. M. Klinck and E. N. Powell. 1996. Modeling the vertical distribution of oyster larvae in response to environmental conditions. Mar. Ecol. Prog. Ser., 136, 97-110.

- 1997. A modeling study of the effects of size-and depth-dependent predation on larval survival. J. Plank. Res., 19, 1583-1598.

Dekshenieks, M. M., E. E. Hofmann and E. N. Powell. 1993. Environmental effects on the growth and development of eastern oyster, Crassostrea virginica (Gmelin, 1791), larvae: A modeling study. J. Shellfish Res., 12, 241-254.

DiBacco, C., D. Sutton and L. McConnico. 2001. Vertical migration behavior and horizontal distribution of brachyuran larvae in a low-inflow estuary: implications for bay-ocean exchange. Mar. Ecol. Prog. Ser., 217, 191-206.

Epperson, B. K., B. McRae, K. Scribner, S. A. Cushman, M. S. Rosenberg, M. J. Fortin, P. James, M. Murphy, S. Manel and P. Legendre. 2010. Utility of computer simulations in landscape genetics. Molec. Ecol., 19, 3549-3564.

Fabens, A. J. 1965. Properties and fitting of the Von Bertalanffy growth curve. Growth, 29, 265-289.

Ford, S. E. 1997. History and present status of molluscan shellfisheries from Barnegat Bay to Delaware Bay, in The History, Present Condition, and Future of the Molluscan Fisheries of North and Central America and Europe, Vol. 1, Atlantic and Gulf Coasts, C. L. MacKenzie, Jr., V. G. Burrell, Jr., A. Rosenfield and W. L. Hobart, eds., U.S. Department of Commerce, NOAA Tech. Rep. 127, 119-140.

Ford, S. E., E. N. Powell, J. M. Klinck and E. E. Hofmann. 1999. Modeling the MSX parasite in eastern oyster (Crassostrea virginica) populations. I. Model development, implementation, and verification. J. Shellfish Res., 15, 135-140.

Ford, S. E. and M. R. Tripp. 1996. Diseases and defense mechanisms, in The Eastern Oyster: Crassostrea virginica, R. I. E. Newell and A. F. Eble, eds., Maryland Sea Grant College, College Park, MD, 581-660.

Frank, B. M., J. J. Piccolo and P. E. Baret. 2011. A review of ecological models for brown trout: towards a new demogenetic model. Ecol. Freshwat. Fish, 20, 167-198.

Gaggiotti, O. E. 1994. Non-equilibrium models in population genetics: stochastic migration and source-sink metapopulations, PhD Thesis, Rutgers University, New Brunswick, NJ, USA.

Galindo, H. M., A. S. Pfeiffer-Herbert, M. A. McManus, Y. I. Chao, F. Chai and S. R. Palumbi. 2010. Seascape genetics along a steep cline: using genetic patterns to test predictions of marine larval dispersal. Molec. Ecol., 19, 3692-3707.

Gawarkiewicz, G., S. Monismith and J. Largier. 2007. Observing larval transport Processes affecting population connectivity progress and challenges. Oceanogr., 20, 40-53.

Grantham, B. A., G. L. Eckert and A. L. Shanks. 2003. Dispersal potential of marine invertebrates in diverse habitats. Ecol. App., 13, 108-116.

Grimm, V., K. Reise and M. Strasser. 2003. Marine metapopulations: a useful concept? Helgoland Mar. Res., 56, 222-228.

Guichard, F., S. A. Levin, A. Hastings and D. Siegel. 2004. Toward a dynamic metacommunity approach to marine reserve theory. Bioscience, 54, 1003-1011.

Gunter, G. 1955. Mortality of oysters and abundance of certain associates related to salinity. Ecology, $36,601-605$. 
Guo, X., D. Hedgecock, W. K. Hershberger, K. Cooper and S. K. Allen Jr. 1998. Genetic determinants of protandric sex in the Pacific oyster, Crassostrea gigas Thunberg. Evolution, 52, 394-402.

Haidvogel, D. B., H. G. Arango, K. Hedstrom, A. Beckmann, P. Malanotte-Rizzoli and A. F. Shchepetkin. 2000. Model evaluation experiments in the North Atlantic Basin: simulations in nonlinear terrain-following coordinates. Dyn. Atmos. Oceans, 32, 239-281.

Hastings, A. and S. Harrison. 1994. Metapopulation dynamics and genetics. Annu. Rev. Ecol. Syst., $25,167-188$.

Hayes, P. F. and R. W. Menzel. 1981. The reproductive cycle of early setting Crassostrea virginica (Gmelin) in the northern Gulf of Mexico, and its implications for population recruitment. Biol. Bull., 160, 80-88.

He, Y., S. Ford, D. Bushek, E. Powell, Z. Bao and X. Guo. 2012. Effective population size of eastern oyster Crassostrea virginica (Gmelin) populations in Delaware Bay, USA. J. Mar. Res., 70, 357379.

Hedgecock, D. 1994. Does variability in reproductive success limit effective population sizes of marine organisms? in Genetics and Evolution of Aquatic Organisms, A. R. Beaumont, ed., Chapman \& Hall, London, 122-134.

Hedgecock, D., P. H. Barber and S. Edmands. 2007. Genetic approaches to measuring connectivity. Oceanography, 20, 70-79.

Hedgecock, D., V. Chow and R. S. Waples. 1992. Effective population numbers of shellfish broodstocks estimated from the temporal variance in allelic frequencies. Aquaculture, 108, 215-232.

Hellberg, M. E. 2009. Gene flow and isolation among populations of marine animals. Annu. Rev. Ecol. Syst., 40, 291-310.

Hofmann, E. E., D. Bushek, S. Ford, X. Guo, D. Haidvogel, D. Hedgecock, J. Klinck, C. Milbury, D. Narváez, E. Powell, Y. Wang, Z. Wang, J. Wilkin and L. Zhang. 2009. Understanding how disease and environment combine to structure resistance in estuarine bivalve populations. Oceanography, 22, 212-231.

Hofmann, E. E., J. M. Klinck, E. N. Powell, S. Boyles and M. Ellis. 1994. Modeling oyster populations 2. Adult size and reproductive effort. J. Shellfish Res., 13, 165-182.

Hofmann, E. E., E. N. Powell, J. M. Klinck and E. A. Wilson. 1992. Modeling oyster populations III. Critical feeding periods, growth and reproduction. J. Shellfish Res., 11, 399-416.

Jensen, A. L. 1997. Origin of the relation between $\mathrm{K}$ and $\mathrm{L}_{\mathrm{inf}}$ and synthesis of relations among life history parameters. Can. J. Fish. Aquat. Sci., 54, 987-989.

Johnson, M. L. and M. S. Gaines. 1990. Evolution of dispersal: theoretical models and empirical tests using birds and mammals. Annu. Rev. Ecol. Syst., 21, 449-480.

Katsanevakis, S. 2009. Population dynamics of the endangered fan mussel Pinna nobilis in a marine lake: a metapopulation matrix modeling approach. Mar. Biol., 156, 1715-1732.

Kennedy, V. S. and C. B. Krantz. 1982. Comparative gametogenic and spawning patterns of the oyster Crassostrea virginica (Gmelin) in central Chesapeake Bay. J. Shellfish Res., 2, 133-140.

Kraeuter, J. N., S. Ford and M. Cummings. 2007. Oyster growth analysis: a comparison of methods. J. Shellfish Res., 26, 479-491.

Kritzer, J. P. and P. F. Sale. 2004. Metapopulation ecology in the sea: from Levins' model to marine ecology and fisheries science. Fish Fisheries, 5, 131-140.

Lamy, T., J. P. Pointier, P. Jarne and P. David. 2012. Testing metapopulation dynamics using genetic demographic and ecological data. Molec. Ecol., 21, 1394-1410.

Landguth E. L.and S. A. Cushman. 2010. CDPOP: A spatially explicit cost distance population genetics program. Molec. Ecol. Resour., 10, 156-161.

Lester, S. E. and B. I. Ruttenberg. 2005. The relationship between pelagic larval duration and range size in tropical reef fishes: a synthetic analysis. Proc. R. Soc. Lond. B Biol. Sci., 272, 585-591. 
Levin, L. A. 2006. Recent progress in understanding larval dispersal: new directions and digressions. Integr. Comp. Biol., 46, 282-297.

Levins, R. 1970. Extinction, in Some Mathematical Problems in Biology, M. Desternhaber, ed., American Mathematical Society, Providence, 77-107.

- 1969. Some demographic and genetic consequences of environmental heterogeneity for biological control. Bul. Entomol. Soc. Amer., 15, 237-240.

Metaxas, A. 2001. Behaviour in flow: perspectives on the distribution and dispersion of meroplanktonic larvae in the water column Can. J. Fish. Aquat. Sci., 58, 86-98.

Narváez, D. A., J. M. Klinck, E. N. Powell, E. E. Hofmann, J. Wilkin and D. Haidvogel. 2012. Modeling the dispersal of eastern oyster (Crassostrea virginica) larvae in Delaware Bay. J. Mar. Res., 70, 381-409.

Palumbi, S. R. 2003. Population genetics, demographic connectivity, and the design of marine reserves. Ecol. App., 13, 146-158.

Pannell, J. R. and B. Charlesworth. 2000. Effects of metapopulation processes on measures of genetic diversity. Phil. Trans. R. Soc. Lond. B Biol. Sci., 355, 1851-1864.

Piggott, M. P., S. C. Banks, P. Tung and L. B. Beheregaray. 2008. Genetic evidence for different scales of connectivity in a marine mollusc. Mar. Ecol. Prog. Ser., 365, 127-136.

Pineda, J. 1999. Circulation and larval distribution in internal tidal bore warm fronts. Limnol. Oceanogr., 44, 1400-1414.

Pineda, J., J. A. Hare and S. Sponaugle. 2007. Larval transport and dispersal in the coastal ocean and consequences for population connectivity. Oceanography, 20, 22-39.

Powell, E. N., K. Ashton-Alcox and D. Bushek. 2011a. Report of the 2011 Stock Assessment Workshop (13th SAW) for the New Jersey Delaware Bay oyster beds. Port Norris, NJ: Haskin Shellfish Research Laboratory Report.

Powell, E. N., K. A. Ashton-Alcox, J. N. Kraeuter, S. E. Ford and D. Bushek. 2008. Long-term trends in oyster population dynamics in Delaware Bay: regime shifts and response to disease. J. Shellfish Res., 27, 729-755.

Powell, E. N., J. M. Klinck, K. A. Ashton-Alcox and J. N. Kraeuter. 2009a. Multiple stable reference points in oyster populations: biological relationships for the eastern oyster (Crassostrea virginica) in Delaware Bay. Fishery Bull., 107, 109-132.

_ 2009b. Multiple stable reference points in oyster populations: implications for reference pointbased management. Fishery Bull., 107, 133-147.

Powell, E. N., J. M. Klinck, X. Guo, S. E. Ford and D. Bushek. 2011b. Can oysters Crassostrea virginica develop resistance to dermo disease in the field: Evaluation using a gene-based population dynamics model. J. Shellfish Res., 30, 685-712.

Powell, E. N., J. M. Klinck, X. Guo, E. E. Hofmann, S. E. Ford and D. Bushek. 2012a. Can oysters Crassostrea virginica develop resistance to dermo disease in the field: The impediment posed by climate cycles. J. Mar. Res., 70, 309-355.

Powell, E. N., J. M. Klinck and E. E. Hofmann. 2011c. Generation time and the stability of sexdetermining alleles in oyster populations as deduced using a gene-based population dynamics model. J. Theor. Biol., 271, 27-43.

Powell, E. N., D. A. Kreeger, J. M. Morson, D. B. Haidvogel, Z. Wang, R. Thomas and J. E. Gius. 2012b. Oyster food supply in Delaware Bay: Estimation from a hydrodynamic model and interaction with the oyster population. J. Mar. Res., 70, 469-503.

Powell, E. N., J. Morson, K. A. Ashton-Alcox and Y. Kim. 2012c. Accommodation of the sex ratio in eastern oysters Crassostrea virginica to variation in growth and mortality across the estuarine salinity gradient in Delaware Bay. J. Mar. Biol. Assn. 
Powell, E. N., J. Morson and J. M. Klinck. 2011d. Application of a gene-based population dynamics model to the optimal egg size problem: why bivalve planktotrophic eggs vary in size? J. Shellfish Res., 30, 403-423.

Powell, E. N. and R. J. Stanton. 1985. Estimating biomass and energy-flow of mollusks in paleocommunities. Palaeontology, 28, 1-34.

Press, W. H., B. P. Flannery, S. A. Teukolsky and W. T. Vettering. 1986. Numerical Recipes, the Art of Scientific Computing, Cambridge Univ Press, Cambridge.

Pujolar, J. M., D. Bevacqua, M. Andrello, F. Capoccioni, E. Ciccotti, G. A. De Leo and and L. Zane. 2011. Genetic patchiness in European eel adults evidenced by molecular genetics and population dynamics modelling. Molec. Phylogen. Evol., 58, 198-206.

Rivera, M. A., K. R. Andrews, D. R. Kobayashi, J. L. K. Wren, C. Kelley, G. K. Roderick and R. J. Toonen. 2011. Genetic analyses and simulations of larval dispersal reveal distinct populations and directional connectivity across a range of the Hawaiian Grouper (Epinephelus quernus). J. Mar. Biol., 2011, 1-11.

Rothschild, B. J. and L. J. Shannon. 2004. Regime shifts and fishery management. Prog. Oceanogr., 60, 397-402.

Scheltema, R. S. 1971. Larval dispersal as a means of genetic exchange between geographically separated populations of shallow-water benthic marine gastropods. Biol. Bull., 140, 284-322.

Shanks, A. L. 2009. Pelagic larval duration and dispersal distance revisited. Biol. Bull., 216, 373-385.

Shanks, A. L. and L. Brink. 2005. Upwelling, downwelling, and cross-shelf transport of bivalve larvae: test of a hypothesis. Mar. Ecol. Prog. Ser., 302, 1-12.

Shanks, A. L., B. A. Grantham and M. H. Carr. 2003. Propagule dispersal distance and the size and spacing of marine reserves. Ecol. App., 13, 159-169.

Shchepetkin, A. F. and J. C. McWilliams. 2005. The regional oceanic modeling system (ROMS): a split-explicit, free-surface, topography-following-coordinate oceanic model. Ocean Model., 9, 347-404.

Siegel, D. A., B. P. Kinlan, B. Gaylord and S. D. Gaines. 2003. Lagrangian descriptions of marine larval dispersion. Mar. Ecol. Prog. Ser., 260, 83-96.

Soletchnik, P., M. Ropert, J. Mazurié, P. G. Fleury and F. Le Coz. 2007. Relationships between oyster mortality patterns and environmental data from monitoring databases along the coasts of France. Aquaculture, 271, 384-400.

Stauber, L. A. 1950. The problem of physiological species with special reference to oysters and oyster drills. Ecology, 31, 109-118.

Strathmann, R. R. 1990. Why life histories evolve differently in the sea. Amer. Zool., 30, 197-207.

Swearer, S. E., J. S. Shima, M. E. Hellberg, S. R. Thorrold, G. P. Jones, D. R. Robertson, S. G. Morgan, K. A. Selkoe, G. M. Ruiz and R. R. Warner. 2002. Evidence of self-recruitment in demersal marine populations. Bull. Mar. Sci., 70, 251-271.

Underwood, A. J. and M. J. Keough. 2001. Supply-side ecology: the nature and consequences of variations in recruitment of intertidal organisms, in Marine Community Ecology, M. D. Bertness, S. D. Gaines and M. E. Hay, eds., Sinauer Associates, Sunderland, 183-200.

Wang, Y., Z. Xu, J. C. Pierce and X. Guo. 2005. Characterization of eastern oyster (Crassostrea virginica Gmelin) chromosomes by fluorescence in situ hybridization with bacteriophage $\mathrm{P} 1$ clones. Mar. Biotechnol., 7, 207-214.

Wang, Z. P., X. M. Guo, S. K. Allen Jr. and R. Wang. 1999. Aneuploid Pacific oyster (Crassostrea gigas Thunberg) as incidentals from triploid production. Aquaculture, 173, 347-357.

Wang, Z., D. Haidvogel, D. Bushek, S. Ford, E. E. Hofmann, E. N. Powell and J. Wilkin. 2012. Circulation and water properties and their relationship to the oyster disease, MSX, in Delaware Bay. J. Mar. Res., 70, 279-308. 
Weersing, K. and R. J. Toonen. 2009. Population genetics, larval dispersal, and connectivity in marine systems. Mar. Ecol. Prog. Ser., 393, 1-12.

White, C., K. A. Selkoe, J. Watson, D. A. Siegel, D. C. Zacherl and R. J. Toonen. 2010. Ocean currents help explain population genetic structure. Proc. R. Soc. Lond. B Biol. Sci., 277, 1685-1694.

Wilson-Ormond, E. A., E. N. Powell and S. M. Ray. 1997. Short-term and small-scale variation in food availability to natural oyster populations: Food, flow and flux. Mar. Ecol., 18, 1-34.

Wright, S. 1951. The genetic structure of populations. Ann. Eugen., 15, 323-354.

Yoo, S. K. and M. S. Yoo. 1972. Biological studies on oyster culture (II) morphological characteristics of the oyster, Crassostrea gigas. J. Kor. Fish. Soc., 6, 65-75.

Received: 10 October, 2011; revised: 20 June, 2012. 